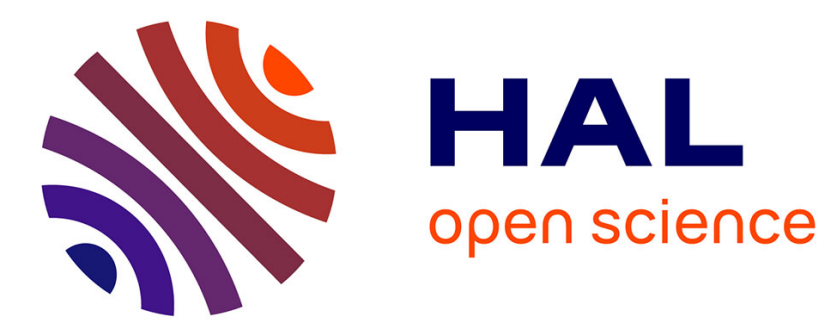

\title{
Impact of crystallinity of poly(lactide) on helium and oxygen barrier properties
}

\author{
A Guinault, C Sollogoub, V Ducruet, Sandra Domenek
}

\section{To cite this version:}

A Guinault, C Sollogoub, V Ducruet, Sandra Domenek. Impact of crystallinity of poly(lactide) on helium and oxygen barrier properties. European Polymer Journal, 2012, 48 (4), pp.779-788. 10.1016/j.eurpolymj.2012.01.014 . hal-01203341

\section{HAL Id: hal-01203341 \\ https://hal.science/hal-01203341}

Submitted on 22 Sep 2015

HAL is a multi-disciplinary open access archive for the deposit and dissemination of scientific research documents, whether they are published or not. The documents may come from teaching and research institutions in France or abroad, or from public or private research centers.
L'archive ouverte pluridisciplinaire HAL, est destinée au dépôt et à la diffusion de documents scientifiques de niveau recherche, publiés ou non, émanant des établissements d'enseignement et de recherche français ou étrangers, des laboratoires publics ou privés. 


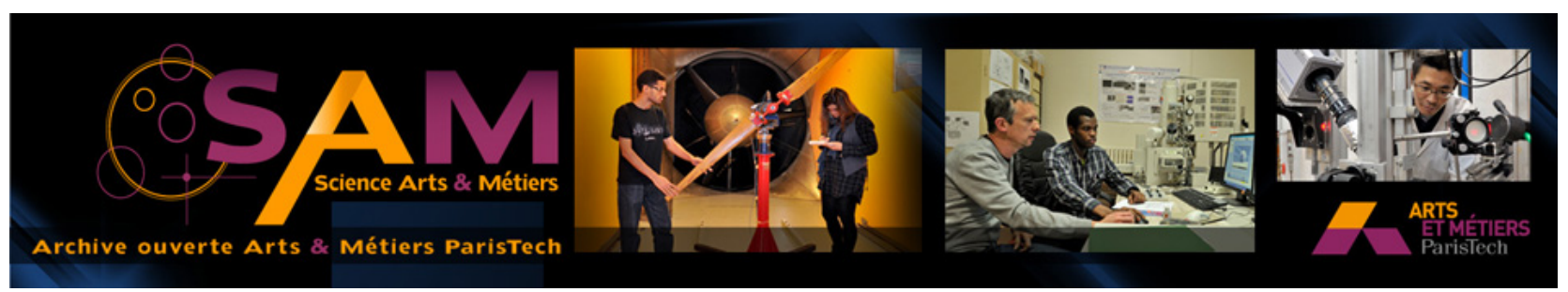

Science Arts \& Métiers (SAM)

is an open access repository that collects the work of Arts et Métiers ParisTech researchers and makes it freely available over the web where possible.

This is an author-deposited version published in: http://sam.ensam.eu

Handle ID: .http://hdl.handle.net/10985/10118

\section{To cite this version :}

A GUINAULT, C SOLLOGOUB, V DUCRUET, Sandra DOMENEK - Impact of crystallinity of poly(lactide) on helium and oxygen barrier properties - European Polymer Journal - Vol. 48, p.779-788 - 2012 


\title{
Impact of crystallinity of poly(lactide) on helium and oxygen barrier properties
}

\author{
Alain Guinault ${ }^{\mathrm{a}, \mathrm{b}}$, Cyrille Sollogoub ${ }^{\mathrm{a}, \mathrm{b}}$, Violette Ducruet $^{\mathrm{c}}$, Sandra Domenek ${ }^{\mathrm{d}, *}$ \\ ${ }^{a}$ Cnam, P-2AM, 292 rue saint Martin, F-75003 Paris, France \\ ${ }^{\mathrm{b}}$ Arts et Métiers Paris Tech, PIMM, 151 boulevard de l'hôpital, F-75013 Paris, France \\ ' INRA, UMR 1145 Ingénierie Procédés Aliments, F-91730 Massy, France \\ d AgroParisTech, UMR 1145 Ingénierie Procédés Aliments, F-91730 Massy, France
}

Keywords:

Poly(lactide)

Poly(lactic acid)

Oxygen permeability

Gas barrier properties

Crystallinity

Rigid amorphous fraction

\begin{abstract}
A B S T R A C T
The helium and oxygen gas barrier properties of poly(lactide) were investigated as a function of stereochemistry and crystallinity degree. Poly(L-lactide) and poly(D,L-lactide) films were obtained by extrusion and thermally cold crystallized in either $\alpha^{\prime}$ - or $\alpha$-crystalline form with increasing crystallinity degree. Annealing of the films at low temperatures yielded to $\alpha^{\prime}$-crystals as well as the creation of a rigid amorphous fraction in the amorphous phase. Unexpectedly, the quantity of the rigid amorphous fraction was highest in poly(L-lactide) crystallized under $\alpha^{\prime}$-form. Unexpectedly, the gas permeability increased with increasing quantity of $\alpha^{\prime}$-crystals in poly(L-lactide) and remained constant with increasing quantity of $\alpha^{\prime}$-crystals in poly(D,L-lactide). A gain in gas barrier properties was obtained upon crystallization at higher temperatures yielding $\alpha$-crystals. The analysis of the oxygen transport parameters, in particular the diffusion and the solubility coefficient showed that the diffusion was accelerated upon crystallization, while the solubility coefficient decreased in an expected manner which led to conclude that it remained constant in the amorphous phase. The acceleration of the diffusion seems to be correlated to the occurrence of the rigid amorphous fraction, which holds larger free volume. To conclude, for optimization of poly(lactide) gas barrier properties by focussing on the decrease of the diffusion coefficient it can be suggested to work with poly(D,L-lactide) and to aim a crystallization in $\alpha$-form avoiding the formation of a rigid amorphous fraction.
\end{abstract}

\section{Introduction}

A novel class of biobased and/or biodegradable polymers is now emerging driven by growing environmental awareness. Poly(lactide), PLA, is actually one of the most used bioplastics, although market penetration is still lacking far behind petrochemical materials. Initially used for biomedical applications, the polymer gathers however several interesting technological properties for commodity applications, such as ease of processing, good clarity, and acceptable mechanical properties. Its oxygen barrier prop-

* Corresponding author. Address: AgroParisTech, 1 rue des Olympiades, F-91744 Massy Cedex, France. Tel.: +33 (0) 169935068.

E-mail address: sandra.domenek@agroparistech.fr (S. Domenek). erties are rather moderated, and can be classified between poly(ethylene terephthalate) and poly(styrene) [1,2].

PLA is a semicrystalline polymer and with this respect increasing crystallinity for obtaining better barrier properties seems to be a good way for optimization. Following the hypothesis of Michaels and Bixler [3] proposed on the basis of their pioneering work on polyethylene, crystalline structures are impenetrable for small, permeating molecules, constituting an excluded volume within the material. The transport of permeates is therefore limited in the amorphous phase, in which they need to adopt a tortuous path. The tortuous path being prolonged, the permeation is delayed by a decrease of the macroscopically observed diffusion coefficient. Furthermore, the creation of crystalline structures decreases the amount of amorphous phase which is available 
for penetrant sorption. Hence, crystallinity acts on both parameters determining permeability, diffusion and solubility coefficient.

Kanehashi et al. [4] published recently a review using a very large number of literature data on the relationship between crystallinity degree and gas barrier properties of common semicrystalline and liquid crystalline polymers including PLA. They showed that in a large number of cases, correlation between crystallinity degree and gas permeability is poor. To give two examples contained in Ref. [4], in the case of semicrystalline syndiotactic poly(styrene) no effect on oxygen permeability is observed upon increasing crystallinity degree. In the case of poly(ethylene terephthalate) large scatter of data did not allow for concluding on an effect of the crystallinity degree.

The relationship between PLA crystallinity degree and gas barrier properties has been subject of a few studies yet [2,5-8]. Comparing the literature data, there are differences in observed behavior for PLA. Sawada et al. [5] observed for poly(D,L-lactide) (4/96), PDLLA, constant oxygen permeability up to roughly $40 \%$ of crystallinity degree and afterwards small decrease. Drieskens et al. [6] showed, still for PDLLA (4/96), decrease in permeability with increasing crystallinity degree, where slope was somewhat steeper for high crystallinity degrees. Colomines et al. [2] observed increase in oxygen permeability with increasing crystallinity for a poly(L-lactide) (PLLA) sample. Dedensification of the amorphous phase $[2,6]$ was suggested for explanation of the observed trends which do not obey the excluded volume hypothesis of Michaels and Bixler [3]. Sawada [5] suggests a continuous space around crystalline regions, due to the stress imposed on macromolecular chains on the interface with the amorphous phases.

On a molecular scale, transport of gaseous molecules in polymers proceeds by jumps which are infrequent in the case of glassy materials. In fact, molecules spend most of the time "rattling" in a microvoid. Jumps occur in the case that a passage of one microvoid to another in the polymer structure is opened by chain movements $[9,10]$. Therefore, transport relies on macromolecular chain dynamics which are restricted in the glassy state yielding infrequent jumps from one position to another. Gas molecules can therefore be regarded as a probe for polymer microstructure.

PLA microstructure has been already widely studied, where PLLA has received far more attention due to its longer history and importance in the biomedical field. PLA crystallizes in different polymorphic forms, the main polymorph obtained by thermal crystallization is the $\alpha$-form, described in 2003 [11]. An important feature with respect to transport is the small density difference between the crystals of PLLA (1.26 by computing [11], 1.290 by experiment [12]) and the amorphous phase (1.24 by experiment [12]). Kawai et al. [13] described in 2007 the $\alpha^{\prime}$-form, which is a distorted $\alpha$-form obtained by thermal crystallization below $90^{\circ} \mathrm{C}$. The $\alpha$-form is yielded at crystallization temperatures higher than $120^{\circ} \mathrm{C}$, between both temperatures, mixtures are obtained [14]. With regards to the amorphous phase, PLA has been described with the help of the three-phase model [15-19], considering besides the crystalline phase two fractions of the amorphous phase, the mobile amorphous fraction (MAF) and the rigid amorphous fraction (RAF). The latter does not relax at the glass transition temperature, because molecules are partially trapped in the crystalline lamellae [20]. In addition, some authors show a confinement effect on the mobile amorphous phase between crystalline lamellae, which develops during crystallization [21-24]. The confined MAF shows a glass transition temperature which is shifted to higher temperatures compared to a fully amorphous sample.

The structure/function relationship between PLA microstructure and transport properties and the role of the crystallinity degree are not understood today. Scarce experimental results are not always coherent. The aim of the present study is thus to go further in the investigation of the action of the crystallinity of PLA on transport properties. In this aim two different PLA grades differing in stereochemistry were probed. Thermal crystallization was carried out with both grades controlling the crystalline form and yielding increasing crystallinity degree with either $\alpha^{\prime}$ - or $\alpha$ crystallites. The transport properties were investigated with the help of helium and oxygen, two molecules differing in their molecular volume.

\section{Material and methods}

\subsection{Sample preparation}

Poly(L-lactide) (PLLA) Biomer L9000 was purchased from Biomer Biopolyesters (Germany). Following the producer its D-lactic acid units content is less than 1\%. Poly(D,L-lactide) (PDLLA) INGEO 2002D was purchased from NatureWorks LLC (USA) and has a percentage of D-lactic acid units of $4.3 \%$ [25].

PLLA and PDLLA pellets were dried under low pressure $\left(10^{4} \mathrm{~Pa}\right)$ for $8 \mathrm{~h}$ at $80^{\circ} \mathrm{C}$ and subsequently extruded by single screw extrusion with a $30 \mathrm{~mm}$ diameter extruder (with a $33 L / D$ (length on diameter) barrel) and a three sections screw without mixing elements. The extruder screw speed was set to $40 \mathrm{rpm}$. The temperature profile of the barrel for the six zones was $180-185-190-195-200-200^{\circ} \mathrm{C}$. The temperature of the mixer device (4 Sulzer SMX ${ }^{\circledR}$ ) and the die was defined at $200{ }^{\circ} \mathrm{C}$. A flat die of $200 \mathrm{~mm}$ width and a chill roll equipment were used to manufacture films of approximately $300 \mu \mathrm{m}$ thickness. The roll temperature was fixed at $20^{\circ} \mathrm{C}$. Two extrusion campaigns were carried out for both grades of PLA.

In order to obtain samples with defined crystallinity the extruded film was themocompressed from the glassy state at $5 \times 10^{4} \mathrm{~Pa}$ with the help of a thermal press (Darragon, France) at defined temperature for defined time. For that, the film samples were sandwiched between two Teflon sheets and two stainless steel plates. After pressing, the sandwich was quickly opened and films were quenched to room temperature at a cold surface. Films were stored at room temperature.

The crystalline morphology of the film samples was observed by using an optical transmission microscope (Nachet, France) under polarized light. The samples were prepared by using a microtome (Leica, France) to yield thin samples of 5-10 $\mu \mathrm{m}$ thickness.

The crystalline structure of the films samples was investigated by wide-angle X-ray scattering (WAXS) by means 
of a X'Pert (Panalytical) diffractometer ( $\mathrm{Cu}-\mathrm{K} \alpha$ radiation). The high voltage was fixed at $40 \mathrm{kV}$ and the tube current was set at $40 \mathrm{~mA}$.

For calorimetric analysis two different DSC equipments were used. Isothermal cold crystallization of as-prepared extruded films was carried out with the help of a Pyris 1 DSC (Perkin Elmer, France) equipped with an intercooler and calibrated with indium and tin standard. Purge gas flow was $30 \mathrm{~mL} \mathrm{~min}^{-1} \mathrm{~N}_{2}$. As-prepared samples (5-10 mg) were loaded into aluminum crucibles at $20^{\circ} \mathrm{C}$. After equilibration a temperature step with maximum speed (approx. $100{ }^{\circ} \mathrm{C} \mathrm{min}^{-1}$ ) to the desired crystallization temperature was performed and isothermal cold crystallization was carried out for $30 \mathrm{~min}$ to $2 \mathrm{~h}$ depending on the PLA grade and crystallization temperature. Samples were then quenched to $0{ }^{\circ} \mathrm{C}$ and analysis of the crystallinity was carried out by reheating the sample at $10^{\circ} \mathrm{C} \mathrm{min}^{-1}$ heating rate up to $200^{\circ} \mathrm{C}$. Tests were performed in duplicate.

The analysis of the glass transition temperature and the crystallinity degree of the film samples produced under the heating press were carried out by means of a Q100 DSC (TA Instruments), equipped with an intercooler. Calibration was performed with the help of an indium standard and calibration of the heat capacity was done with the help of a sapphire standard. The purge gas flow was $50 \mathrm{~mL} \mathrm{~min}^{-1}$ $\mathrm{N}_{2}$. For analysis of the crystallinity degree, as-prepared samples (5-8 $\mathrm{mg}$, loaded in aluminum Tzero crucibles) were heated at constant heating rate of $10^{\circ} \mathrm{C} \mathrm{min}^{-1}$ from 10 to $190^{\circ} \mathrm{C}$. The degree of crystallinity $\left(\chi_{\mathrm{c}}\right)$ of the PLA samples was calculated after

$\chi_{\mathrm{c}}=\frac{\Delta H_{\mathrm{m}}-\Delta H_{\mathrm{cc}}}{\Delta H_{\mathrm{m}}^{0}}$

where $\Delta H_{\mathrm{m}}$ is the enthalpy of melting after subtraction of the small exothermal event at the beginning of the melting peak, $\Delta H_{\mathrm{cc}}$ is the enthalpy of cold crystallization, and $\Delta H_{\mathrm{m}}^{0}$ is the enthalpy of fusion per mol of repeating unit of the perfect crystal of infinite size (the totally crystalline polymer), taken to be $93 \mathrm{~J} \mathrm{~g}^{-1}$ [26] for comparison reasons with current literature.

The analysis of the glass transition was carried out in the modulated mode of the Q100 (TA Instruments) DSC. Samples were rejuvenated prior to analysis at $74{ }^{\circ} \mathrm{C}$ during 20 min. The modulated temperature program used was published by Delpouve et al. [21]. The samples were heated from 10 to $90^{\circ} \mathrm{C}$ at an average heating rate of $2{ }^{\circ} \mathrm{C} \mathrm{min}^{-1}$, on which a temperature modulation with an amplitude of $0.318^{\circ} \mathrm{C}$ (heat only mode) and a period of $60 \mathrm{~s}$ was superposed. The glass transition temperature was taken at the midpoint of the transition. The heat capacity change of the amorphous samples, $\Delta C_{P, 0}$, was measured as follows: the extruded sample was melted at $200{ }^{\circ} \mathrm{C}$ for $5 \mathrm{~min}$ and subsequently quenched to $20^{\circ} \mathrm{C}$ in the DSC apparatus. Then, the modulated temperature program was carried out. $\Delta C_{P, 0}$ of the PLLA sample amounted to $0.569 \pm 0.001 \mathrm{Jg}^{-1}{ }^{\circ} \mathrm{C}^{-1}$ and of the PDLLA sample to $0.520 \pm 0.013 \mathrm{~J} \mathrm{~g}^{-1}{ }^{\circ} \mathrm{C}^{-1}$. All measurements were made in duplicate or triplicate on each sample subjected to permeation.

The quantity of the mobile amorphous fraction (MAF) was computed after
$\mathrm{MAF}=\frac{\Delta C_{\mathrm{P}}}{\Delta C_{\mathrm{P}, 0}}$

The percentage of the rigid amorphous fraction (RAF) was computed with the help of the relationship:

$\mathrm{MAF}+\mathrm{RAF}+\chi_{c}=100 \%$

The helium permeability was measured at room temperature and $0 \% \mathrm{RH}$, by a specific lab-made analyser, based on the ISO 15105-2:2003 method. The helium permeability was determined from the transmission rate by taking into account the thickness of the films.

The oxygen permeability was measured with a Systech analyser 8001 at $23{ }^{\circ} \mathrm{C}$ and $0 \% \mathrm{RH}$. Oxygen permeability is calculated from the measured oxygen transmission rate (OTR) by multiplying it by the sample thickness (measured with at micrometer on 9 points). For assessing reproducibility of permeability measurements were carried out on at least two different samples obtained by the same temperature protocol. Diffusion $(D)$ and sorption $(S)$ coefficients were calculated with the help of the time-lag method. The time lag ( $\left.t_{\text {lag }}\right)$ was obtained by calculating the intercept on the abscissa of the cumulated flux curve, and $D$ was found by evaluating

$t_{\text {lag }}=\frac{L^{2}}{6 D}$

where $L$ is the sample thickness. The sorption coefficient was obtained with the help of the general relationship

$P=D \cdot S$

where $P$ denotes the permeability.

\section{Results and discussion}

\subsection{PLA sample morphology}

In order to follow the barrier properties of the two different PLA grades in function of the material crystallinity, a preliminary DSC study was carried out in the aim of specifying experimental conditions for the realization of different sample morphologies.

Isothermal crystallization experiments were done in order to measure crystallization half times of the two PLA grades at temperatures able to yield $\alpha^{\prime}$ or $\alpha$ crystalline form. Table 1 summarizes the characteristics of the whole sample set. It gives the measured crystallization half times at the chosen experimental temperatures. Maximum crystallization rates of PLA are described to be located at $110^{\circ} \mathrm{C}$ for PLLA and PDLLA independent of the stereochemistry [7,27-30]. In accordance, we find the smallest crystallization half time closest to $110^{\circ} \mathrm{C}$, at $120^{\circ} \mathrm{C}$. Furthermore, it can be clearly seen in Table 1 that the increase in D-lactic acid content in the polymer chain leads to higher crystallization half time, which is a result already described [27,31,32].

With the help of the isothermal data, time/temperature conditions for cold crystallization were chosen to produce samples of large diameter with different crystallinity degree under the heating press. For enabling a permeability measurement the film diameter needs to be higher than $10 \mathrm{~cm}$. There is an experimental difficulty of producing 
Table 1

Characteristics of PLLA and PDLLA samples.

\begin{tabular}{|c|c|c|c|c|c|c|c|c|c|c|}
\hline & $T\left[{ }^{\circ} \mathrm{C}\right]$ & $t_{1 / 2}[\mathrm{~min}]$ & Form & $t[\mathrm{~min}]$ & $\Delta H_{\mathrm{m}}[\mathrm{J} / \mathrm{g}]$ & $\chi[\%]$ & $T_{\mathrm{g}}\left[{ }^{\circ} \mathrm{C}\right]$ & $\Delta C_{\mathrm{P}}\left[\mathrm{J} / \mathrm{g}^{\circ} \mathrm{C}\right]$ & MAF [\%] & RAF [\%] \\
\hline \multirow[t]{8}{*}{ PLLA } & Extruded & & & & $2.7 \pm 1.6$ & $3 \pm 2$ & $60 \pm 1$ & $0.437 \pm 0.005$ & $77 \pm 1$ & $20 \pm 3$ \\
\hline & 85 & $11.9 \pm 0.5$ & $\alpha^{\prime}$ & 10 & $12.7 \pm 1.9$ & $14 \pm 2$ & $58 \pm 1$ & $0.331 \pm 0.022$ & $58 \pm 4$ & $28 \pm 6$ \\
\hline & & & & 30 & $37.1 \pm 0.2$ & $40 \pm 1$ & $64 \pm 1$ & $0.236 \pm 0.017$ & $41 \pm 3$ & $19 \pm 3$ \\
\hline & & & & 90 & $35.3 \pm 2.0$ & $38 \pm 2$ & $64 \pm 1$ & $0.237 \pm 0.040$ & $41 \pm 7$ & $21 \pm 9$ \\
\hline & 90 & $6.8 \pm 0.5$ & $\alpha^{\prime}$ & 5 & $3.9 \pm 0.7$ & $4 \pm 1$ & $59 \pm 1$ & $0.536 \pm 0.040$ & $94 \pm 7$ & $1 \pm 8$ \\
\hline & & & & 30 & $35.4 \pm 2.7$ & $38 \pm 3$ & $64 \pm 1$ & $0.220 \pm 0.018$ & $39 \pm 3$ & $23 \pm 6$ \\
\hline & 120 & $2.5 \pm 0.5$ & $\alpha$ & 30 & $54.2 \pm 2.3$ & $58 \pm 2$ & $63 \pm 1$ & $0.207 \pm 0.017$ & $36 \pm 3$ & $5 \pm 5$ \\
\hline & 140 & $5.6 \pm 0.5$ & $\alpha$ & 30 & $57.0 \pm 1.4$ & $61 \pm 1$ & $61 \pm 2$ & $0.217 \pm 0.011$ & $38 \pm 2$ & $1 \pm 3$ \\
\hline \multirow[t]{12}{*}{ PLLA } & Extruded & & & & $1.9 \pm 0.7$ & $2 \pm 1$ & $57 \pm 2$ & $0.454 \pm 0.024$ & $87 \pm 5$ & $11 \pm 5$ \\
\hline & 85 & $36 \pm 7$ & $\alpha^{\prime}$ & 10 & $1.5 \pm 0.1$ & $2 \pm 1$ & $59 \pm 1$ & $0.482 \pm 0.028$ & $93 \pm 5$ & $6 \pm 5$ \\
\hline & & & & 30 & $13.2 \pm 1.2$ & $14 \pm 1$ & $59 \pm 1$ & $0.398 \pm 0.024$ & $77 \pm 5$ & $9 \pm 6$ \\
\hline & & & & 60 & $29.2 \pm 0.9$ & $31 \pm 1$ & $61 \pm 1$ & $0.313 \pm 0.013$ & $60 \pm 3$ & $8 \pm 4$ \\
\hline & & & & 90 & $30.7 \pm 0.2$ & $33 \pm 1$ & $62 \pm 2$ & $0.293 \pm 0.015$ & $56 \pm 3$ & $11 \pm 3$ \\
\hline & & & & 480 & $32.6 \pm 1.2$ & $35 \pm 1$ & $64 \pm 1$ & $0.273 \pm 0.003$ & $52 \pm 1$ & $13 \pm 2$ \\
\hline & 90 & $20.4 \pm 0.5$ & $\alpha^{\prime}$ & 10 & $3.0 \pm 0.1$ & $3 \pm 1$ & $58 \pm 2$ & $0.431 \pm 0.034$ & $83 \pm 7$ & $14 \pm 7$ \\
\hline & & & & 30 & $12.5 \pm 2.8$ & $13 \pm 3$ & $58 \pm 3$ & $0.364 \pm 0.043$ & $70 \pm 8$ & $16 \pm 11$ \\
\hline & 120 & $6.7 \pm 0.5$ & $\alpha$ & 30 & $35.7 \pm 1.5$ & $38 \pm 2$ & $59 \pm 2$ & $0.251 \pm 0.040$ & $48 \pm 8$ & $13 \pm 9$ \\
\hline & & & & 480 & $41.0 \pm 2.0$ & $44 \pm 2$ & $60 \pm 1$ & $0.251 \pm 0.023$ & $48 \pm 4$ & $8 \pm 7$ \\
\hline & 135 & $23 \pm 3$ & $\alpha$ & 90 & $37.4 \pm 2.0$ & $40 \pm 2$ & $58 \pm 1$ & $0.316 \pm 0.008$ & $61 \pm 2$ & $0 \pm 4$ \\
\hline & & & & 480 & $41.0 \pm 1.9$ & $44 \pm 2$ & $58 \pm 1$ & $0.271 \pm 0.048$ & $52 \pm 9$ & $4 \pm 11$ \\
\hline
\end{tabular}

$T$ crystallization temperature; $t_{1 / 2}$ crystallization half time; t crystallization time of the sample; $\Delta H_{\mathrm{m}}$ melting enthalpy.

$\chi$, crystallinity degree; $T_{\mathrm{g}}$, glass transition temperature; $\Delta C_{\mathrm{p}}$, heat capacity change at glass transition; MAF, mobile amorphous fraction; RAF, rigid amorphous fraction.

large film samples with calibrated crystallinity degree due to the time needed for temperature stabilization inside the heating press. Small crystallinity degrees could therefore only be yielded for low temperature conditions where crystallization half times were long. Following the literature conditions using the three-phase model [21], to produce samples including different quantities of RAF and yielding confinement of the amorphous phase, the crystallization time has to be prolonged far above crystallization half time. Table 1 gives the time/temperature conditions chosen in consequence. The maximum crystallinity degree achieved for PLLA was $61 \%$, while it was only $44 \%$ in the case of PDLLA (Table 1).

Fig. 1 shows the micrographs of the structures obtained. Comparing the pictures obtained at $90{ }^{\circ} \mathrm{C}$ with those obtained at $120^{\circ} \mathrm{C}$, it seems that a lower crystallization temperature yields to smaller crystals. However, in any case, crystallites were difficult to observe after cold crystallization and were too small for quantitative size determination by optical microscopy.

WAXS measurements were carried out for the crystallized samples at different experimental temperatures, choosing the samples with the highest crystallinity degree. Typical results are given in Fig. 2 and the observed crystalline form is summarized in Table 1 . As shown by Cocca et al. [33], the crystalline structure of PLLA which depends on the crystallization temperature can be determined with the help of the characteristic reflexion (Fig. 2a and c). At low crystallization temperature $\left(90^{\circ} \mathrm{C}\right)$, PLLA exhibits an $\alpha^{\prime}$ structure characterized by a the reflection at $2 \theta=24.5^{\circ}$ which is absent in the sample crystallized at $140^{\circ} \mathrm{C}$. At higher temperature $\left(140^{\circ} \mathrm{C}\right)$, one observes furthermore that the reflections of the $(100 / 200)$ and (203) shift to higher $2 \theta$, that the intensity of the $(010)$ reflection increases and the reflection (103) appears. Small diffraction peaks (Fig. 2c) appear also with increasing crystallization temper-
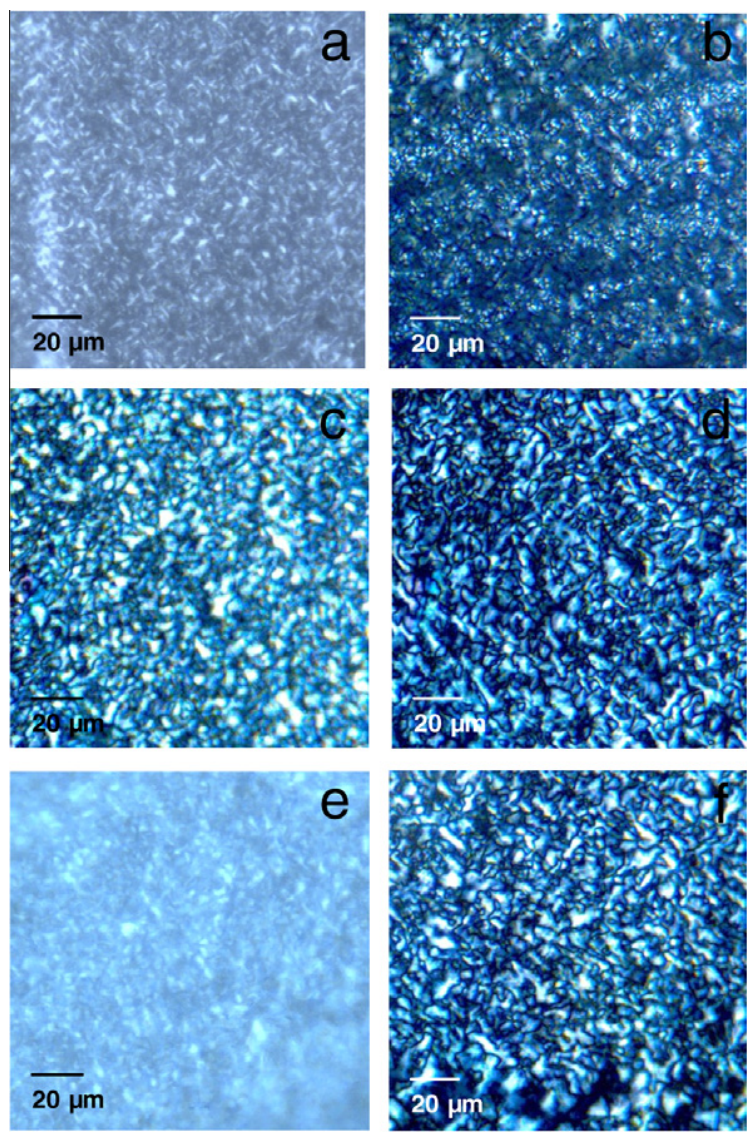

Fig. 1. POM micrographs of PLLA (a, $c$ and e) and PDLLA (b, $d$ and $f$ ) after different crystallization procedures. (a and b) $90^{\circ} \mathrm{C}, 30 \mathrm{~min}$; (c and d) $120^{\circ} \mathrm{C}, 30 \mathrm{~min}$; (e) $140{ }^{\circ} \mathrm{C}, 30 \mathrm{~min}$, (f) $135^{\circ} \mathrm{C}, 90 \mathrm{~min}$. 

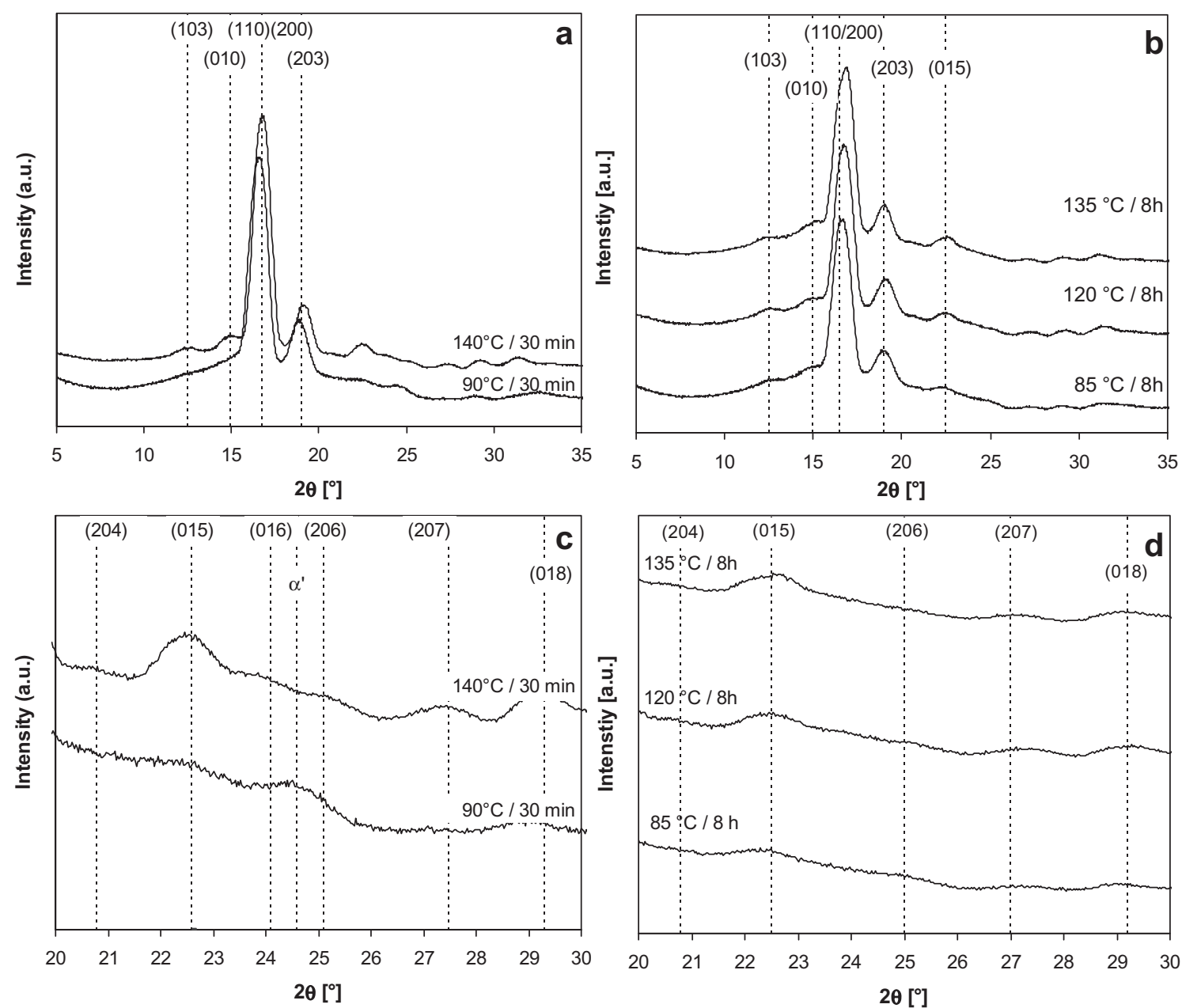

Fig. 2. WAXS data for PLLA (a and c) and PDLLA (b and d) crystallized at different temperatures.

ature at 20.8 (204), $22.6(015), 24.1(016)$ and $25.1^{\circ}(206)$. The peaks at $27.50(207)$ and $29.3^{\circ}(018)$ appear instead of the reflection at $27^{\circ}$ in the sample crystallized at $90^{\circ} \mathrm{C}$.

The peak intensities of the PDLLA samples were lower than those of PLLA and are shown in Fig. $2 \mathrm{~b}$ (zoomed spectrum Fig. 2d). One observes (Fig. 2b) the slight shift of the reflections of the $(110) /(200)$ and (203) planes at higher crystallization temperatures and the intensity of the (103) and (015) reflections increases. The small reflexions were difficult to measure. Increase of intensity with increasing crystallization temperature was seen for the (015), (207) and (018) plane reflections. We concluded for a change of crystalline form from $\alpha^{\prime}$ to $\alpha$ with increasing temperature for both PLA stereochemistries, which is in accordance with current literature [13,33].

Taking together information on crystalline form and crystallinity degree, data show that the maximum crystallinity degree obtained in $\alpha^{\prime}$-form was $40 \%$ in the case of PLLA and 35\% in the case of PDLLA (Table 1). In the aim to obtain higher crystallinity degrees, higher temperatures corresponding to crystallization in $\alpha$ form needed to be chosen. Fig. 3 shows the development of the shape of the glass transition with increasing crystallinity of the different PLA samples for PLLA (Fig. 3a) and PDLLA (Fig. 3b). The glass transition broadened with increasing crystallinity degree where the high temperature end shifted towards higher temperatures. A numerical measure is the glass transition temperature $\left(T_{\mathrm{g}}\right)$, which increased with crystallization temperature increase (Table 1). Broadening of the glass transition was described by different authors, in most cases for PLLA [15,21,22,24]. In the case of long annealing times at $85^{\circ} \mathrm{C}$, an important $T_{\mathrm{g}}$ shift of approximately $6{ }^{\circ} \mathrm{C}$ was found for both grades of PLA. This indicated confinement of the mobile amorphous phase fraction (MAF) inside the crystalline structure, as it was described by Delpouve et al. [21]. In the case of PDLLA, at high temperature $\left(120^{\circ} \mathrm{C}\right)$ and long annealing times, the shift of $T_{\mathrm{g}}$ was much smaller, though. This would indicate that confinement effect was less important when crystallization from the glassy state was carried out at high temperature.

The step height of $\Delta C_{\mathrm{p}}$ decreased with increasing annealing time and temperature since it is proportional to quantity of amorphous phase (Table 1 ). An interesting exception was that the $\Delta C_{p}$ of the extruded sample was 

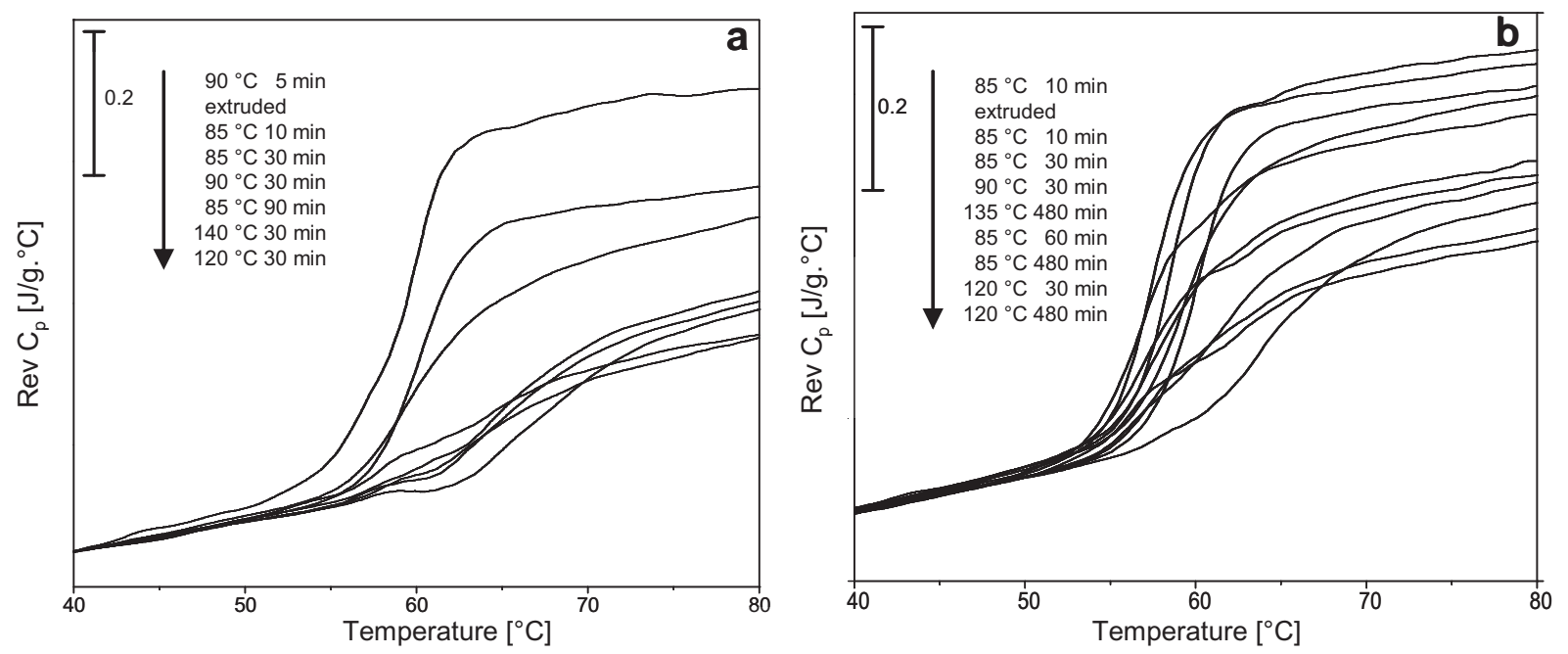

Fig. 3. Evolution of the glass transition signal with increasing crystallization time and temperature of PLLA (a) and PDLLA (b).

smaller compared to the very little crystalline sample $85^{\circ} \mathrm{C} / 10 \mathrm{~min}$. With the help of the crystallinity degree and the quantity of amorphous phase relaxing at $T_{\mathrm{g}}$, the quantity of rigid amorphous fraction (RAF) was estimated (Eq. (3), values reported in Table 1). It appeared that the RAF of the extruded PLLA and the extruded PDLLA was higher than the $90^{\circ} \mathrm{C} / 5 \mathrm{~min}$ sample and higher than the $85^{\circ} \mathrm{C} / 10 \mathrm{~min}$ sample, respectively, while crystallinity degrees were equal. We suggest that the drawing, although very faint, of the film in the chill roll equipment might induce some constraining of the amorphous phase, which reduces its ability to relax at glass transition. In the case of PLLA, we observe an increase of RAF for the samples cold-crystallized in $\alpha^{\prime}$-form. The quantity of RAF in PLLA is consistent with the literature data $[16,17,21]$ obtained in similar conditions, which show between $15 \%$ and $25 \%$ of RAF at $33-40 \% \chi_{c}$. Bras et al. [24] worked with dielectric relaxation spectra and proposed by extrapolation a value of $20 \%$ RAF in the case of semicrystalline PLLA samples with $\chi_{c}$ higher than $40 \%$. There is however, scatter on our data, which is most probably related to the fabrication method of large samples under the heating press, while the literature studies are generally done in the DSC apparatus, where temperature is far better controlled. At high annealing temperatures where PLA crystallized in $\alpha$ form no RAF could be evidenced in our samples, though. In the case of the PDLLA grade, RAF quantities were smaller compared to PLLA and significant amounts were only evidenced for long annealing times at $85^{\circ} \mathrm{C}$. Similarly to PLLA, no RAF could be observed when annealing temperatures were high enough to yield $\alpha$ crystallites.

To conclude, different sample morphologies were prepared in order to test structure/function relationships for gas barrier properties. Samples were crystallized in two different crystalline forms, $\alpha$ and $\alpha^{\prime}$. Furthermore, annealing times were increased far above crystallization half time, in order to yield different amounts of RAF in the amorphous phase.

\subsection{Gas barrier properties}

The gas barrier properties of the sample set were analyzed with the help of two molecular probes, helium and oxygen, differing in their size and critical temperature. Helium has a very small kinetic diameter $(0.260 \mathrm{~nm})$, small critical volume $\left(57.5 \AA^{3}\right)$ and low condensability, with a critical temperature of $5.3 \mathrm{~K}$. Oxygen $\left(\mathrm{O}_{2}\right)$ has higher kinetic diameter $(0.364 \mathrm{~nm})$, higher critical volume $\left(73.5 \AA^{3}\right)$ and much higher critical temperature (155 K) (data from [34]). Generally, increasing critical volume of a gas scales with decrease in the diffusion coefficient, while increasing critical temperature scales with increase in the solubility coefficient. It has been shown by Mueller Plathe [35] and Takeuchi [9] that oxygen transport proceeds by the "red sea mechanism". Helium transport on the other hand is much more "fluid like" with much lower time elapsing between jumps due to its comparatively smaller size [36]. Helium permeability through polymers is higher than oxygen permeability (e.g. [37]), which has as a very practical consequence a notable decrease in measurement times. In the present case, the experiment time for helium was in the order of $30 \mathrm{~min}$ in comparison of two days for oxygen. Helium permeability is therefore a good screening tool for gas permeation. However, molecular transport mechanisms are slightly different, as oxygen transport is more sensitive to free volume fluctuations $[9,35,36]$.

The change in helium permeability through PLA samples cold-crystallized to different crystallinity degrees and presenting either $\alpha^{\prime}$ - or $\alpha$-crystals is shown in Fig. 4. A first, methodological conclusion is that there is dispersion of values, linked to inherent heterogeneity of the films. This is shown by the points corresponding to the extruded samples which were measured as produced and intercalated all along the measurement series. Repeat measurements on one film were carried out in the $120^{\circ} \mathrm{C}$ series, showing a standard deviation of $6 \%$ for one film. Due the relatively high permeability, the observed lag-times in the 


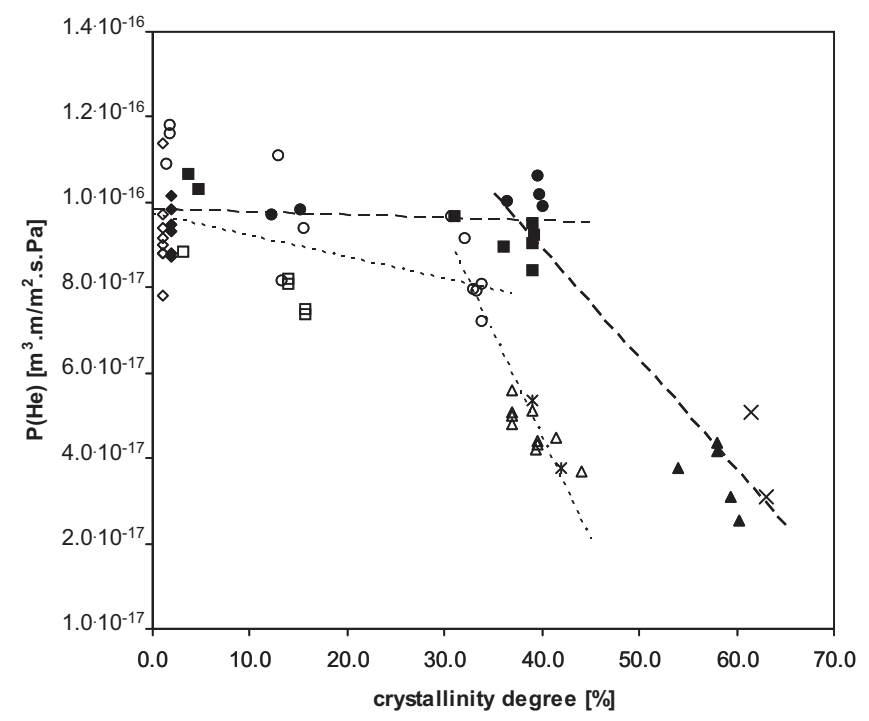

Fig. 4. Helium permeability of PLLA (filled symbols) and PDLLA (open symbols) samples crystallized at different time and temperatures. Lines are linear regression lines drawn to guide the eye. Symbols indicated the time/temperature conditions of the crystallization treatment: $\diamond$ extruded sample, $\bigcirc 85^{\circ} \mathrm{C}$, $\square$ $90{ }^{\circ} \mathrm{C}, \triangle 120^{\circ} \mathrm{C}, * 135^{\circ} \mathrm{C}$ (PDLLA), X $140^{\circ} \mathrm{C}$ (PLLA).

experiment were small and thus very sensitive to experimental error. Therefore, interpretation of diffusion coefficients was not attempted here. To account for uncertainty linked to the control of the time/temperature conditions under the heating press, experiments were reproduced and results not averaged. Therefore there is some scatter also on the crystallinity degree for one experimental condition. Despite experimental difficulty and scatter on the data, different conclusions could be drawn. There seems to be a difference in the behavior of samples cold-crystallized in $\alpha^{\prime}$-form compared to $\alpha$-form and a difference linked to the stereochemistry. Let's take the example of PLLA coldcrystallized in $\alpha^{\prime}$-form at $85^{\circ} \mathrm{C}$ for times up to $90 \mathrm{~min}$, which is roughly nine times the crystallization half time. The maximum crystallinity degree was $35 \%$. The glass transition temperature was shifted up by $6^{\circ} \mathrm{C}$ (Table 1 ), which shows confinement of the amorphous phase, and the RAF accounted for $21 \%$. No significant difference between helium permeability of the extruded sample and the fully crystallized sample can be observed (Fig. 4). In order to increase crystallinity degree, a higher crystallization temperature needs to be chosen, in our case $120^{\circ} \mathrm{C}$ which yields formation of $\alpha$ crystals. In this case helium permeability dropped although absolute gain in barrier properties was small, roughly a factor two. For fully crystallized samples, crystallites in the $\alpha^{\prime}$-form seem to have no influence on helium barrier properties, in contrary to crystallites in $\alpha$-form. In the case of PDLLA a small decrease in helium permeability could be observed upon cold crystallization in $\alpha^{\prime}$ form, but similar to PLLA, a much steeper drop was observed upon cold crystallization in $\alpha$ form.

In order to further investigate the transport properties of the PLA samples in function of crystallinity degree and crystallite form, the diffusion and solubility coefficients need to be analyzed. Therefore, oxygen transport, which is slower and more sensitive to microstructure, was analyzed. In
Fig. 5 are plotted the results of the same sample set. On the left side are given results of PLLA and on the right, results of PDLLA. Curve shapes are similar to the picture obtained with the help of helium permeability measurements. In Fig. 5 results were also compared to the literature data [5,6]. Data from Drieskens et al. [6] correspond to cold crystallization of PDLLA (4/96) at $125^{\circ} \mathrm{C}$ and different times. Preponderance $\boldsymbol{\alpha}$-form can be assumed. Data from Sawada et al. [5] were recorded for solvent cast PDLLA (4/ 96) samples cold crystallized at temperatures ranging from 70 to $150{ }^{\circ} \mathrm{C}$ for $48 \mathrm{~h}$. Therefore, the highest crystallinity degree of approximately $50 \%$ can be assumed to correspond to $\alpha$-crystals, while the others would be $\alpha^{\prime}$-crystals, a result also suggested by the WAXS profiles published in the article. Comparison of PDLLA permeability data shows good concordance with Drieskens's data [6]. Correspondence to Sawada's data [5] is lower because Sawada et al. [5] measured at higher temperature $\left(35^{\circ} \mathrm{C}\right)$. Absolute permeability values are also in concordance with data published by Courgneau et al. [7].

Upon comparing curve shapes between PLLA (Fig. 5a) and PDLLA (Fig. 5b) one observes that in the case of PDLLA there is small reduction of the permeability with increasing crystallinity up to approximately 35\%, no matter which crystalline form ( $\alpha$-form represented by data from Drieskens et al. [6]. After that value, permeability decrease is steeper. In contrary, in the case of PLLA, permeability increases with increasing crystallinity, which is a counterintuitive result with regards to the excluded volume hypothesis, postulated by Michaels and Bixler [3]. The same result is obtained by Sawada et al. [5] for PDLLA (Fig. 5b) and by Colomines et al. [2] for PLLA. After exceeding a crystallinity degree of approximately $40 \%$, crystalline form changes and permeability decreases. To go further in analysis the evolution of the diffusion coefficient ( $D$, Fig. $5 c$ and $d)$ and the solubility coefficient ( $S$, Fig. 5e and f) with increasing 

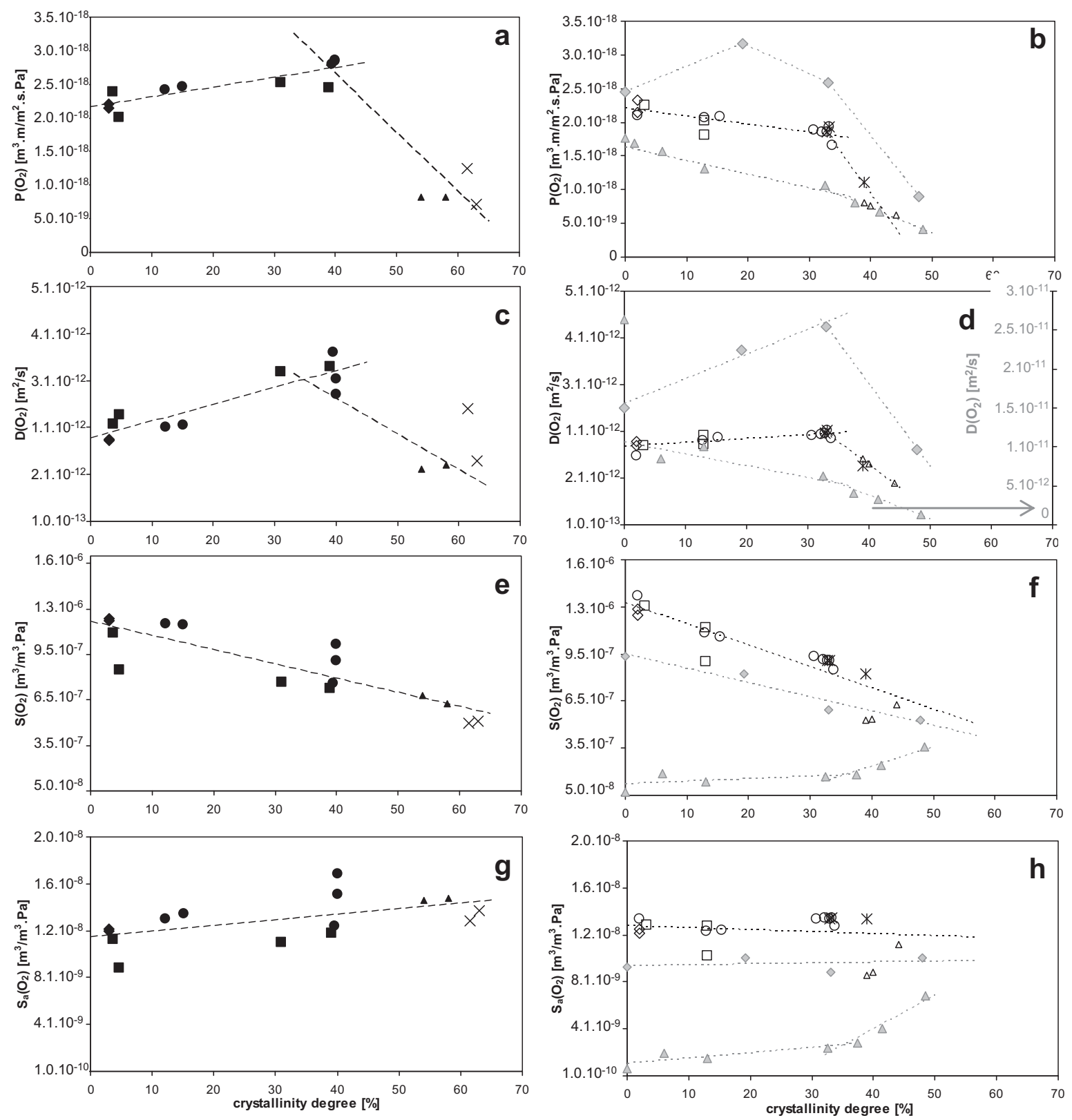

Fig. 5. Oxygen permeability $(P)$, diffusion coefficient $(D)$, sorption coefficient $(S)$ and normalized sorption coefficient $\left(S_{a}\right)$ as a function of crystallinity degree. PLLA samples are shown on the left column (a, c, e and g) and PDLLA samples are shown on the right column (b, d, f and h). Symbols indicate time/ temperature conditions of the crystallization treatment for PLLA(filled symbols) and PDLLA (open symbols): $\diamond$ extruded sample, $\bigcirc 85^{\circ} \mathrm{C}$, $\square 90{ }^{\circ} \mathrm{C}, \triangle 120{ }^{\circ} \mathrm{C}$, $* 135^{\circ} \mathrm{C}, \mathrm{X} 140{ }^{\circ} \mathrm{C}, \triangle$ data of Drieskens et al.[6] for crystallization at $125^{\circ} \mathrm{C}$, data of Sawada et al.[5] for crystallization at $70,80,90$, and $150{ }^{\circ} \mathrm{C}$.

crystallinity degree was investigated. It can be observed that $D$ was constant with increasing crystallinity degree for PDLLA crystals in $\alpha^{\prime}$-form (Fig. $5 \mathrm{~d}$ ) and that even extensive crystallization treatment at $85^{\circ} \mathrm{C}$ did not yield any change. $D$ increased moreover in the case of PLLA with crystallinity degree (Fig. 5c). The solubility coefficient decreased monotonically with increasing crystallinity (Fig. 5e and f). The decrease of the solubility coefficient with increasing crystallinity can be explained by the smaller volume available for sorption in the sample mass. The solubility coefficient of the amorphous phase $\left(S_{\mathrm{a}}\right)$ was obtained by normalizing measured bulk solubility to the mass fraction of the amorphous phase

$S_{\mathrm{a}}=\frac{S}{1-\chi}$

The data of $S_{\mathrm{a}}$ are given in Fig. $5 \mathrm{~g}$ and $\mathrm{h}$. Within the error of the measurements, no evolution of $S_{a}$ for PDLLA containing $\alpha^{\prime}$-crystals was observed and a small increase can be seen in the case of PLLA. $S_{\mathrm{a}}$ is an appreciative value not corrected by the density difference between the amorphous and crystalline phase. Our results are consistent with 
results obtained by Sawada et al. [5] who worked at low annealing temperatures. Data of Drieskens et al. [6], who worked at high annealing temperatures, show different behavior. The authors found a continuous decrease in $D$ and an increase in $S$ with crystallinity degree.

The importance of the crystalline form for permeability has been observed also very recently by Cocca et al. [33]. They showed that the water vapor permeability of completely crystallized PLLA samples diminished with increasing fraction of crystals in $\alpha$-form. For explaining the constant value or even the increase of gas permeability with increasing crystallinity degree, different hypothesis have been proposed in the literature. Dedensification of the amorphous phase was cited by Colomines et al. [2] and Drieskens et al. [6]. Sawada et al. [5] suggested a continuous space around crystalline regions.

Following the tortuosity concept, a decrease of $D$ and $S$ with increasing crystallinity is expected. In the case of poly(ethylene terephthalate) (PET), permeability decrease with increasing crystallinity only relies on the drop of $D$ and a rise of $S$ what has been evidenced by several authors [38-40]. The effect was explained by dedensification of the amorphous phase, which increases oxygen solubility. Hu et al. [39] showed that the density of the intralamellar amorphous phase inside the spherulites is smaller compared to the density of amorphous PET. They attribute the dedensification to increased constraints on the amorphous phase macromolecular chains due to their attachment to crystallites. This effect causes the glass transition to shift to higher temperatures [40], which is also observed in our case and in the case of Drieskens' publication for PLA. In the case of PLA the shift of the $T_{\mathrm{g}}$ was attributed to the confinement of the MAF, though [21-24], as the RAF is not able to relax in the region of the glass transition. In our data, we cannot observe an increase in $S$ with increasing crystallinity degree. The dedensification hypothesis seems to work, when PLA is crystallized in $\alpha$-form and/or when RAF is low. In other words, the gas barrier properties for one degree of crystallinity might be determined by the presence of RAF.

In the case of cold crystallization of PLLA into $\alpha^{\prime}$-form, a specific amount of RAF is measured and the diffusion coefficient increases (Fig. 5c). PDLLA (Fig. 5d) shows less RAF and almost no evolution in D. Data at very low crystallinity degrees most probably correspond to samples where spherulites are not space-filling. Therefore only a small tortuosity effect can be expected. However incomplete spacefilling cannot explain an acceleration of $D$. Space seems to be created around crystalline lamellae which accelerates the diffusion coefficient but does not introduce increased oxygen solubility. One reason might be that PLA seems to have lower oxygen solubility compared to PET [4]. Del Rio et al. [41] studied very recently the evolution of free volume in crystallized PLLA with the help of Positron Annihilation Lifetime Spectroscopy (PALS) measurements. They observed an increase in free volume upon annealing which they located primarily inside the RAF. The free volume hole size decreased from 95.7 to $86.5 \AA^{3}$ upon annealing of PLLA at $100{ }^{\circ} \mathrm{C}$ up to a crystallinity degree of $36.5 \%$, but quantity of holes increased. The morphology of the free volume thus changed towards smaller, but more frequent voids having an "opener" structure in the semi crystalline compared to the amorphous polymer. Duda and Zielinski [42] showed that increase in free volume increases the diffusion process. The free volume theory predicts that diffusion is dominated by the scarcity of free volume and that specific molecular interactions are of secondary importance, particularly in the case of poorly interacting molecules as it is the case in the present system. An "opener" [41] structure might thus imply higher connectivity in order to allow transport [42]. Basically speaking, more small voids are more efficient than some large ones. Arnoult et al. [16] showed furthermore that the quantity of RAF per unit of crystallinity of PLLA was much lower than the one of PET. PLA remained fragile when RAF was formed, where else PET went strong. The authors concluded that PLA presents only a weak coupling between amorphous and crystalline phases. Zuza et al. [17] compared fragility parameters of PLLA and PDLLA and showed that PDLLA is a stronger glass former than PLLA. In conclusion we suggest that there is decoupling between crystalline and amorphous phase with a RAF adjacent to crystalline lamellae holding increased free volume. This increment in free volume offers a preferential pathway for diffusion yielding a higher macroscopic diffusion coefficient. The effect is more pronounced when more RAF is present.

\section{Conclusion}

The relationship between PLA crystallinity degree and gas barrier properties was investigated. For helium as for oxygen, permeability was higher through PLLA compared to PDLLA at the same degree of crystallinity. The creation of crystallites in $\alpha^{\prime}$-form inside the polymer matrix showed unexpectedly no effect on the measured permeability. The analysis of oxygen diffusion and solubility coefficient in PLA as a function of crystallinity degree showed that permeability was primarily governed by the diffusion coefficient. For crystallinity degrees lower than around 35\%, the diffusion coefficient increased with increasing crystallinity degree which was attributed to the creation of a rigid amorphous fraction including larger free volume. The amount of rigid amorphous fraction was higher in the PLLA sample compared to the PDLLA sample and seemed to be higher when annealing was carried out at low temperatures leading to the creation of $\alpha^{\prime}$-crystallites. In summary, there seemed to be different behavior in function of crystalline form and of PLA stereochemistry. This indicates that more detailed studies of the structure/barrier properties relationship are needed, where stereochemistry and crystalline form are controlled and also because RAF amount differences stayed low in regard of the effect on the gas permeability.

The presented results suggest however, that optimization of PLA gas barrier properties should focus on tortuosity as solubility effects seem not to offset gains in the diffusion coefficient as it is the case in crystallization of PET.

\section{Acknowledgement}

The authors acknowledge Dr. Olivier Vitrac for his precious technical support in computer programming. 


\section{References}

[1] Auras R, Singh SP, Singh JJ. Evaluation of oriented poly(lactide) polymers vs. existing PET and oriented PS for fresh food service container. Packag Technol Sci 2005;18:207-16.

[2] Colomines G, Ducruet V, Courgneau C, Guinault A, Domenek S Barrier properties of poly(lactic acid) and its morphological changes induced by aroma compound sorption. Polym. Int. 2010;59(6): 818-26.

[3] Michaels AS, Bixler HJ. Journal of Polymer Science 1961;50:393-412.

[4] Kanehashi S, Kusakabe A, Sato S, Nagai K. Analysis of permeability; solubility and diffusivity of carbon dioxide; oxygen; and nitrogen in crystalline and liquid crystalline polymers. J. Membr. Sci 2010;365(1-2):40-51.

[5] Sawada H, Takahashi Y, Miyata S, Kanehashi S, Sato S, Nagai K. Gas transport properties and crystalline structure of poly(lactic acid) membranes. Trans. Mater. Res. Soc. Jpn 2010;35:241-6.

[6] Drieskens M, Peeters R, Mullens J, Franco D, Lemstra PJ, HristovaBogaerds DG. Structure versus properties relationship of poly(lactic acid). I. Effect of crystallinity on barrier properties. J Polym Sci Part B: Polym Phys 2009;47(22):2247-58.

[7] Courgneau C, Domenek S, Lebossé R, Guinault A, Averous L, Ducruet V. Effect of crystallization on barrier properties of formulated polylactide. Polymer Int 2012;61:180-9.

[8] Colomines G, Domenek S, Ducruet V, Guinault A. Influences of the crystallisation rate on thermal and barrier properties of polylactide acid (PLA) food packaging films. Int J Mater Form 2008;1:607-10.

[9] Takeuchi H. A jump motion of small molecules in glassy-polymers a molecular-dynamics simulation. J Chem Phys 1990;93(3):2062-7.

[10] Theodorou DN. Molecular simulations of sorption and diffusion in amorphous polymers. In: Neogi P, editor. Editor. New York: Marcel Dekker, Inc.; 1996. p. 67-142.

[11] Sasaki S, Asakura T. Helix distortion and crystal structure of the alpha-form of poly(L-lactide). Macromolecules 2003;36(22): 8385-90.

[12] Auras R, Harte B, Selke S. An overview of polylactides as packaging materials. Macromol Biosci 2004;4:835-64.

[13] Kawai T, Rahman N, Matsuba G, Nishida K, Kanaya T, Nakano M et al. Crystallization and melting behavior of poly(L-lactic acid). Macromolecules 2007;40(26):9463-9.

[14] Zhang J, Tashiro K, Tsuji H, Domb AJ. Disorder-to-order phase transition and multiple melting behavior of poly(L-lactide) investigated by simultaneous measurements of WAXD and DSC. Macromolecules 2008;41(4):1352-7.

[15] Pyda M, Wunderlich B. Reversing and nonreversing heat capacity of poly(lactic acid) in the glass transition region by TMDSC. Macromolecules 2005;38:10472-9.

[16] Arnoult M, Dargent E, Mano JF. Mobile amorphous phase fragility in semi-crystalline polymers: comparison of PET and PLLA. Polymer 2007;48(4):1012-9.

[17] Zuza E, Ugartemendia JM, Lopez A, Meaurio E, Lejardi A, Sarasua R. Glass transition behavior and dynamic fragility in polylactides containing mobile and rigid amorphous fractions. Polymer 2008:1-6.

[18] Magon A, Pyda M. Study of crystalline and amorphous phases of biodegradable poly(lactic acid) by advanced thermal analysis. Polymer 2009;50(16):3967-73.

[19] Wang Y, Funari DS, Mano JF. Influence of semicrystalline morphology on the glass transition of poly(L-lactic) acid. Macromol Chem Phys 2006;207:1262-71.

[20] Wunderlich B. Reversible crystallization and the rigid-amorphous phase in semicrystalline macromolecules. Prog Polym Sci 2003;28(3):383-450.
[21] Delpouve N, Saiter A, Mano J, Dargent E. Cooperative rearranging region size in semi-crystalline poly(L-lactic acid). Polymer 2008;49:3130-5

[22] Mano J. Structural evolution of amorphous phase during crystallization of poly(L-lactic acid): a synchrotron wide-angle Xray scattering study. J Non-Cryst Solids 2007;353:2567-72.

[23] Mano JF, Gómez Ribelles JL, Alves NM, Salmerón Sanchez M. Glass transition dynamics and structural relaxation of PLLA studied by DSC: influence of crystallinity. Polymer 2005;46(19):8258-65.

[24] Bras AR, Malik P, Dionisio M, Mano JF. Influence of crystallinity in molecular motions of poly(L-lactic acid) investigated by dielectric relaxation spectroscopy. Macromolecules 2008;41(17):6419-30.

[25] Li Y, Wu H, Wang Y, Liu L, Han L, Wu J, et al. Synergistic effects of PEC and MWCNTs on crystallization behavior of PLLA. J Polym Sci Part B Polym Phys 2010;48(5):520-8.

[26] Fischer E, Sterzel H, Wegner G. Investigation of structure of solution grown crystals of lactide copolymers by means of chemical reactions. Colloid Polym Sci 1973;251:980-90.

[27] Kolstad JJ. Crystallization kinetics of poly( L-lactide-co-meso-lactide) J Appl Poly Sci 1996;62(7):1079-91.

[28] Xiao H, Liu F, Jiang T, Yeh J-T. Kinetics and crystal structure of isothermal crystallization of poly(lactic acid) plasticized with triphenyl phosphate. J Appl Poly Sci 2010;117(5):2980-92.

[29] Xiao HW, Li P, Ren X, Jiang T, Yeh J-T. Isothermal crystallization kinetics and crystal structure of poly(lactic acid): effect of triphenyl phosphate and talc. J Appl Poly Sci 2010;118(6):3558-69.

[30] Di Lorenzo ML. The crystallization and melting processes of poly( $\mathrm{L}-$ lactic acid). Macromol Symp 2006;234(1):176-83.

[31] Huang J, Lisowski MS, Runt J, Hall ES, Kean RT, Buehler N, et al Crystallization and microstructure of poly(L-lactide-co-mesolactide) copolymers. Macromolecules 1998;31(8):2593-9.

[32] Ling X, Spruiell J. Analysis of the complex thermal behavior of poly(Llactic acid) film. I. Samples crystallized from the glassy state. J Polym Sci Part B: Polym Phys 2006;44:3200-14.

[33] Cocca M, di Lorenzo ML, Malinconico M, Frezza V. Influence of crystal polymorphism on mechanical and barrier properties of poly(L-lactic acid). Eur Polymer J 2011;47:1073-80.

[34] Park HB, Lee YM. Polymeric membrane materials and potential in gas separation. In: Li NN, Fane AG, Ho WSW, Matsuura T, editors. Hoboke. New Jersey, USA: John Wiley \& Sons; 2008. p. 633-70.

[35] Mueller Plathe F. Molecular-dynamics simulation of gas-transport in amorphous polypropylene. J Chem Phys 1992;96(4):3200-5.

[36] Sok RM, Berendsen HJC, Vangunsteren WF. Molecular-dynamics simulation of the transport of small molecules across a polymer membrane. J Chem Phys 1992;96(6):4699-704

[37] Matteucci S, Yampolskii Y, Pinnau I, Freeman BD. Transport of gases and vapors in glassy and rubbery polymers. In: Yampolskii Y, Pinnau I, Freeman BD, editors. Chichester. UK: John Wiley \& Sons; 2006. p. 1-48.

[38] Sekelik DJ, Stepanov EV, Nazarenko S, Schiraldi D, Hiltner A, Baer E. Oxygen barrier properties of crystallized and talc-filled poly(ethylene terephthalate). J Polym Sci Part B: Polym Phys 1999;37(8):847-57.

[39] Hu YS, Hiltner A, Baer E. Improving oxygen barrier properties of poly(ethylene terephthalate) by incorporating isophthalate. II. Effect of crystallization. J Appl Poly Sci 2005;98(4):1629-42.

[40] Liu RYF, Hu YS, Schiraldi DA, Hiltner A, Baer E. Crystallinity and oxygen transport properties of PET bottle walls. J Appl Poly Sci 2004;94(2):671-7.

[41] del Rio J, Etxeberria A, Lopez-Rodriguez N, Lizundia E, Sarasua JR. A PALS contribution to the supramolecular structure of poly(L-lactide) Macromolecules 2010;43(10):4698-707.

[42] Duda JL, Zielinski JM. In: Neogi P, editor. Free volume theory. New York: Marcel Dekker, Inc.; 1996. p. 143-71. 